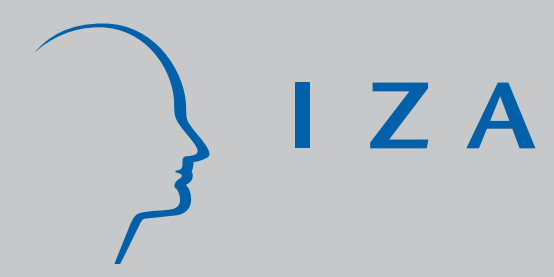

IZA DP No. 3920

The Effect of Receiving Supplementary UI Benefits on Unemployment Duration

Tomi Kyyrä

Pierpaolo Parrotta

Michael Rosholm

J anuary 2009 


\title{
The Effect of Receiving Supplementary UI Benefits on Unemployment Duration
}

\author{
Tomi Kyyrä \\ VATT Helsinki, Aarhus School of Business and CIM \\ Pierpaolo Parrotta \\ Aarhus School of Business and CIM \\ Michael Rosholm \\ Aarhus School of Business, CIM and IZA
}

Discussion Paper No. 3920

January 2009

IZA

P.O. Box 7240

53072 Bonn

Germany

Phone: +49-228-3894-0

Fax: +49-228-3894-180

E-mail: iza@iza.org

\begin{abstract}
Any opinions expressed here are those of the author(s) and not those of IZA. Research published in this series may include views on policy, but the institute itself takes no institutional policy positions.

The Institute for the Study of Labor (IZA) in Bonn is a local and virtual international research center and a place of communication between science, politics and business. IZA is an independent nonprofit organization supported by Deutsche Post World Net. The center is associated with the University of Bonn and offers a stimulating research environment through its international network, workshops and conferences, data service, project support, research visits and doctoral program. IZA engages in (i) original and internationally competitive research in all fields of labor economics, (ii) development of policy concepts, and (iii) dissemination of research results and concepts to the interested public.
\end{abstract}

IZA Discussion Papers often represent preliminary work and are circulated to encourage discussion. Citation of such a paper should account for its provisional character. A revised version may be available directly from the author. 
IZA Discussion Paper No. 3920

January 2009

\title{
ABSTRACT
}

\section{The Effect of Receiving Supplementary UI Benefits on Unemployment Duration*}

\begin{abstract}
We consider the consequences of working part-time on supplementary unemployment insurance benefits in the Danish labour market. Following the "timing-of-events" approach we estimate causal effects of subsidized part-time work on the hazard rate out of unemployment insurance benefit receipt. We find evidence of a negative lock-in effect and a positive posttreatment effect, both of which vary across individuals. The resulting net effect on the expected unemployment duration is positive for some groups (e.g. married women) and negative for others (e.g. young workers).
\end{abstract}

JEL Classification: C41, J65

Keywords: unemployment benefits, part-time work, lock-in effect, treatment effect, duration analysis

Corresponding author:

Michael Rosholm

Institute of Economics

Aarhus School of Business

Prismet, Silkeborgvej 2

DK-8000 AARHUS C

Denmark

E-mail: rom@asb.dk 


\section{Introduction}

Flexibility in labour markets has become a key issue in Europe in the wake of persistently high unemployment rates. A number of strategies have been pursued in order to increase labour market flexibility, ranging from Flexicurity systems, aimed at increasing flexibility directly, to temporary work contract schemes, aiming at increasing flexibility in inherently inflexible labour markets. Interestingly, in both types of regimes, the same types of policy instruments are used to some extent, e.g. active labour market policies, and the topic of this paper, supplementary unemployment benefits in some form. Thus, several forms of supplementary or partial unemployment benefits have emerged in almost all European countries and in North America, aimed at making it more attractive for otherwise unemployed workers to accept part-time or short-term employment (atypical jobs), and hence increase overall employment and production. Supplementary benefits are specifically aimed at supplementing the income of part-time workers who are looking for full-time work and to improve the unemployed workers' incentives to accept such employment. However, the presence of the supplementary unemployment benefits may produce disincentives or in some cases facilitate forms of moral hazard behaviour. Specifically, such benefits could discourage workers from searching for regular employment due to the relatively high replacement rates and/or prolonged benefit periods associated with working part-time and receiving supplementary benefits. Thus, the potential for both positive and negative consequences of supplementary benefits implies that the desirability of such a policy is an empirical question, which needs to be answered empirically.

In this paper, we study supplementary unemployment insurance (UI) benefits and their use in Denmark. Specifically, we first examine which unemployed workers are more likely to experience a transition into parttime work with supplementary UI benefits. Secondly, we analyze the effect of supplementary UI benefit provision on the hazard rate out of UI benefit receipt. That is, we seek to answer the counterfactual question 'what would have happened to these workers had they not received supplementary UI benefits'. The counterfactual situation in this case consists of remaining in full-time unemployment. Thus, we evaluate the effect of working part-time (say, $x$ hours per week) and receiving supplementary UI benefits for the rest, that is, $37-x$ hours, since 37 hours correspond to full-time employment. We also briefly discuss the benefits and costs of such a scheme: on the one hand, there are reduced costs of UI, and there is a corresponding increase in production from their part-time employment. On the other hand, they might 
have found full-time employment faster in the absence of supplementary UI benefits, and there may be various types of distortionary effects.

The empirical analysis is conducted on a flow sample of Danish workers becoming unemployed in 1996-2006 and receiving full-time UI benefits. Some of these workers eventually enter part-time employment and receive supplementary UI benefits. In this paper, such a period is considered as part of the unemployment spell, in order to enable the causal analysis outlined above. The data includes particularly detailed information concerning weekly receipt of UI benefits and supplementary UI benefits, as well as a vast amount of information which may be translated into explanatory variables.

The econometric model is based on the "timing-of-events" approach to modelling causal effects in duration models (Abbring \& Van den Berg, 2003). Following this approach, the causal effect of receiving supplementary UI benefits can be separately identified from the selection effect without imposing any exclusion restrictions. In addition, the model enables an analysis of so-called lock-in and post-treatment effects, that is, time-varying effects of supplementary UI benefits.

We find evidence of a significant lock-in effect: being on supplementary UI benefits lowers the transition rate out of benefits. In addition, we find a positive post-treatment effect of having received supplementary UI benefits. We proceed to estimating heterogeneous effects for sub-groups of unemployed workers and calculate the effect on the expected remaining unemployment duration for those different groups and also describe the distribution of effects. For example, we find that receipt of supplementary UI benefits has positive implications for young workers: subsidized parttime work reduces the expected remaining time in unemployment for them. Hence, making supplementary UI benefits available to young workers may be an interesting labour market policy instrument, in the sense that (subsidized) part-time work can serve as a stepping stone to regular employment.

The structure of the paper is as follows: the next section summarizes the debate on the role of part-time and temporary jobs; the $3^{\text {rd }}$ section briefly outlines the Danish regulatory system of supplementary UI benefits; the $4^{\text {th }}$ sections depict details on the data set and the main descriptive statistics. The econometric model is outlined in section 5 , and the results are discussed in the $6^{\text {th }}$ section. Section 7 contains a conclusion, a brief discussion of costbenefit analytical aspects, and some policy considerations. 


\section{The Literature and Debate on Part-Time Em- ployment}

Part-time and temporary jobs in the labour market are part of what is usually labelled as 'atypical employment'. These jobs are often occupied by individuals who have difficulties obtaining regular full-time employment, and in other cases, having a part-time job is simply a rational voluntary choice. The supplementary UI benefit scheme is naturally aimed at the first group of individuals. To the extent that those who would work part-time anyway receive supplementary UI benefits, it is fraud ${ }^{1}$ and may result in a considerable deadweight loss.

Some researchers have argued that part-time jobs (and other atypical jobs) may act as stepping stones toward regular and more stable work. First of all, in some cases temporary and part-time jobs can represent the only way of escaping (full-time) unemployment. Secondly, those jobs can be adopted by employers as useful screening (or signalling) devices for permanent job positions (Storrie, 2002; Houseman, Kalleberg \& Erickcek, 2003). Thirdly, they can provide valuable skills, work experience and in some cases facilitate the acquisition of specific human capital. Finally, they may induce individuals to enlarge their job network (labour market contacts) and consequently increase their possibilities for obtaining full-time employment.

On the other hand, there may be disadvantages of subsidizing temporary and part-time jobs: they may just postpone the (full-time) unemployment experience (Larsson, Lindqvist \& Skans, 2005) and thus lengthen the time until regular employment. Part-time employment is often associated with uncertainty about future income and working hours, and consequently, it is difficult to make investment and savings decisions, to obtain credit, make child care arrangements and so on. The high concentration of low-skilled and less educated workers in part-time jobs may indicate that some of these jobs are dead-end, since firms may not be planning to hire these workers on full-time basis, limiting thus their possibilities to improve upon their future situation (Heinrich, Mueser \& Troske, 2005). Moreover, the promotion of temporary and part-time jobs as a way of increasing the degree of labour market flexibility is believed by some authors to be undesirable, especially in countries where Employment Protection Legislation is not particularly strong (such as in Denmark) and flexibility is already high. As pointed out

\footnotetext{
${ }^{1}$ In order to receive supplementary UI benefits in Denmark, your unemployment insurance must be for more hours than your actually work, that is, you are insured against full-time unemployment and supposed to be looking for full-time employment.
} 
by Booth, Dolado \& Frank (2002), individuals lacking regular jobs for a long period or falling several times into the temporary or part-time work regime may irredeemably damage their career prospects and long-term earnings opportunities.

A number of studies have discussed the role of public policy instruments to compensate and possibly overcome the adverse effects related to temporary and part-time jobs (Rasmussen, Lind \& Visser, 2004; Møller \& Lind, 2000). Specifically, supplementary UI benefits provide financial incentives to accept part-time jobs, that may not be acceptable without subsidies. However, as already discussed above, the availability of such benefits may induce forms of fraud - when persons who would never be interested in full-time employment suddenly qualify for them - and 'moral hazard behaviour' - an individual receiving supplementary UI benefits has a financial incentive to intentionally delay getting a full-time job by searching less intensively than what is optimal from society's point of view. On the other hand, an intensive active labour market policy may actually induce unemployed individuals to search actively for employment (Rosholm, 2008), so to the extent that the availability for full-time employment of supplementary UI benefit recipients can be tested, the fraud and moral hazard risks of a generous income compensation regime (such as the Danish Flexicurity model) may be overcome to quite some extent by intensive monitoring and sanction policies, see also Svarer (2007).

Only a few studies exit treating the role of supplementary UI benefits on search effort and the nature of subsequent employment. The first study we found is Munts (1970), who analyzes whether supplementary benefits encourage or discourage search for regular work. He provides evidence on individual workers receiving partial benefits in Wisconsin and finds that workers adjust their part-time work to gain from combined earnings and benefits. Holen and Horowitz (1974) confirmed and strengthened the conclusions reached by Munts.

McCall (1996), instead, studies whether the level of the earnings disregard influences an UI recipient's job search behaviour. ${ }^{2}$ The analysis is performed on US data, since the amount of earnings disregarded varies across states and within states over time. Thus, developing and using a continuous-time job search model, McCall shows that an increase in the level of earnings disregard generally increases both the part-time and over-

\footnotetext{
${ }^{2}$ The level of disregard is the earnings threshold above which a recipient cannot receive the full amount of benefits but just a part of it (the amount is reduced on a dollar-for dollar basis).
} 
all re-employment hazards. Specifically, an increase in the level of disregard causes higher transition rates from full-time unemployment to subsidized part-time employment during the first three months of unemployment.

Moreover, McCall (1997), using a Canadian Survey, points out that whereas recipients not qualified for partial unemployment benefits are characterized by increasing part-time and full-time reemployment hazard as benefits are exhausted, those qualified for partial benefits show increasing fulltime reemployment hazard but decreasing part-time hazards. He states that the discrepancy occurs because part-time jobs are subsidized and then the value of the subsidy for the former category decreases as benefits are exhausted. In addition, he found that women have longer joblessness duration and higher propensity to be re-employed as part-timers than men.

In sum, Munts (1970), Holen and Horowitz (1974) and McCall (1996, 1997) provide evidence that availability of partial unemployment benefits induces the unemployed to take up subsidized part-time jobs. However, these studies are not informative on whether occupying such jobs subsequently helps unemployed workers find regular full-time jobs and hence reduce the overall duration of unemployment benefit receipt, which is the topic of the present study.

The paper most closely related to our study is Kyyrä (2008), which examines the effects of the receipt of supplementary UI benefits (due to a subsidized part-time job or full-time job shorter than 4 weeks) on the exit rate from unemployment to regular employment in the Finnish labour market. Using a timing-of-events duration model, he finds a notable increase in the exit rate following receipt of supplementary benefits, but no evidence of lock-in effects. Hence, subsidized working on supplementary benefits reduces the expected duration until regular employment. This effect appeared to be weaker for subsidized part-time work than for short full-time work. A major weakness of the Finnish study is a relatively small number of observations on supplementary benefit recipients, which hampered attempts to detect heterogeneity in the effects across individuals. In the present study, impact heterogeneity will play a central role.

Thus, the supplementary benefits seem to produce positive as well as negative effects, depending on the specific circumstances and incentives facing the individuals. Hence, rules and regulations concerning supplementary benefits and part-time work can significantly influence the effort spent on job search and/or the level of reservation wages for regular employment. From the recipient's point of view, the opportunity cost associated with the provision of supplementary benefits depends crucially on the willingness to find a regular job and varies over the receiving period. Therefore, the con- 
clusive remarks here are that the effects of receiving supplementary benefits should be evaluated along spells of unemployment, allowing for potential events occurring in such periods (namely, treatments in the form of parttime employment with supplementary UI benefits), and the effects of these events may depend upon individual characteristics. Before turning to the discussion of the empirical model and results, the Danish regulatory system of supplementary UI benefits and the data used in the analysis are described.

\section{Supplementary UI Benefits in Denmark}

As in most countries, in Denmark supplementary UI benefits are supplements to the weekly earned income for persons working part-time. The minimum requirement to receive supplementary benefits is membership of an unemployment insurance fund and working part-time during a week. Obviously, workers have to meet several other requirements in order to be entitled to supplementary UI benefits. Individuals receiving earnings-related UI benefits have been working and contributing insurance payments to an UI fund. The regulation concerning those forms of earnings compensation differs between full-time and part-time insured. By definition, a full-time insured member is on part-time when his working hours in a week are less than 37 hours, and he is entitled to supplementary UI benefits if his working hours are reduced with more than 7.4 hours in a week. Thus if he works 29.6 hours or more in a week, he is not entitled to supplementary UI benefits. A part-time insured worker is entitled to receive supplementary UI benefits if his working hours are reduced with more than $20 \%$ of his average weekly working hours before unemployment. ${ }^{3}$

The exhaustion of the entitlement period for supplementary UI benefits depends on whether an individual has a part-time job with or without terms of notice. In the former case, the worker can at the maximum receive supplementary benefit for 52 weeks within 70 weeks. When he has done so, the right to receive supplementary UI benefit is ceased until he has worked more than 30 hours a week for 26 weeks within the last 12 months. ${ }^{4}$ However, the rules as described above imply that an unemployed individual who has received supplementary UI benefits for 51 weeks and thereafter refrains from receiving benefits for 19 weeks, can regain the supplementary benefit for an additional 52 weeks, and so on.

The rules are much easier in the absence of term of notice. In this

\footnotetext{
${ }^{3}$ BEK nr 966 08/11/2001, §12, stk.1,2.

${ }^{4}$ BEK nr 966 08/11/2001, § 5, stk. 1,2.
} 
case, the right to receive supplementary benefits is not limited to 52 weeks but instead to four years. After this period one can receives benefits for additional four years by working full-time for 52 weeks within three years. Finally, with or without terms of notice, supplementary UI benefits can at maximum be received for four years within a six-year period.

During the year 2006, 124,947 persons received supplementary UI benefits: this number corresponds to 11,738 full-time unemployed workers. ${ }^{5}$ The number of recipients of supplementary UI benefits, measured as full-time unemployed, went up from 1999 to 2004. In 1999 there were approximately 11,500 recipients. This number peaked in 2004 with more than 14,000 recipients. During 2005 and 2006 the number fell to the level of 2001. However, the trend concerning the number of recipients has not followed the level of unemployment. Unemployment fell from 1999, where it was just above 5\%, to 2002 , increased until 2004 and has fallen again since then. In 2006, the unemployment rate was just below $4 \%$, and today, October 2008, it stood at $1.6 \%$. Over the same period, the fraction of full-time equivalent supplementary UI benefit receivers to the number of unemployed has grown steadily.

\section{Data and Descriptive Statistics}

The data used here is an $8 \%$ random sample of the Danish population entering unemployment in the period covering the years 1996-2006, and who were insured against full-time unemployment. ${ }^{6}$ The sample consists of 74,571 individuals experiencing a total of 240,675 unemployment spells. The data is based on administrative registers used for administrating UI payments, assignments of individuals to active labour market programs etc., and is made available to us by the Danish Central Labour Market Authority (Arbejdsmarkedsstyrelsen). The data is thus considered highly reliable.

An unemployed person is classified as a recipient of supplementary UI benefits in a given week if he or she was not participating in any kind of active labour market programs and if the reduction in benefits corresponds to more than 7.4 hours (implying part-time work of 29.6 hours or less). An

\footnotetext{
${ }^{5}$ One reason for this large number is that a person who becomes unemployed or leaves unemployment in the middle of a week will receive supplementary benefits for the remainder of that week. This is just a consequence of the fact that UI benefits are calculated on a weekly basis in Denmark. Another reason is that they only receive benefits for part-time unemployment, down to 7.4 hours per week.

${ }^{6}$ Close to $80 \%$ of the Danish labour force are members of an UI fund, while the remainder are eligible for social assistance, which is lower, should they become unemployed.
} 
unemployment spell is defined as a sequence of weeks during which a person receives either full-time UI benefits, supplementary UI benefits, participates in some type of active labour market program, or receives a related income transfer (such as sickness payments while unemployed, holiday payments while unemployed etc.). That is, part-time employment coupled with supplementary UI benefits is here treated as part of the unemployment spell in order to enable the counterfactual analysis. Unemployment spells continuing until the end of the sample period (the $24^{\text {th }}$ week of 2007) are treated as independently right-censored observations (less than $2 \%$ of all spells).

Single weeks of supplementary UI benefit receipt that lie during the first or last week of an unemployment spell are not treated as supplementary UI benefit receipt. The reason for this is that such one-week periods are probably due to the timing of job loss or the start of a regular job during the week. ${ }^{7}$ Since the implemented econometric model cannot deal with selection at time zero, we further restrict our sample to those who initially received full-time UI benefits by excluding 6,605 spells that start with receipt of supplementary UI benefits (for a period longer than one week). Exclusion of these spells does not matter much to our results (see Section 6.6).

The dependent variable in the study is the unemployment duration measured in weeks. The two explanatory variables of primary interest are the time-varying indicator for current receipt of supplementary UI benefits, and the time-varying indicator for having received supplementary UI benefits earlier during the current unemployment spell. Furthermore, we have access to background information concerning family status (married or not), gender, age ( 6 categories), ethnic origin ( 5 groups), current area of residence (14 counties), UI fund (9 occupation/industry-related funds). Finally, we include a few variables describing past labour market history, specifically, 3 variables measuring the fraction of time in which the individual received any public income transfers, not just those related to unemployment, in each of the past 3 years, and another variable measuring the number of weeks in the past 2 years that an individual was unemployed, and indicators for the year and quarter of entry into the current unemployment spell. All covariates, except for the two of main interest, are measured at the beginning of the unemployment spell and will be treated as time-invariant regressors, which are fixed for each single spell but can vary over different spells for the same person.

Table 1 shows descriptive statistics when the sample has been split into

\footnotetext{
${ }^{7}$ Say, if the job is lost on Wednesday, then the UI benefits for that week are reduced by working days, corresponding to 14 hours.
} 
two groups - those who did and those who did not receive supplementary UI benefits during their unemployment spell. Descriptive statistics for the entire population are not provided since the chosen random sample is representative. Note that the observations refer to unemployment spells, not to individuals.

Of 234,070 unemployment spells, 43,392 spells (19\%) involve receipt of supplementary UI benefits. These spells are much longer on average (48 vs. 16 weeks). The average time until the first receipt of supplementary UI benefits is 15 weeks (not reported in the table). Among those who received supplementary UI benefits, the mean duration of supplementary UI benefit periods is 3.6 weeks and the average number of such periods, separated by full-time unemployment, during a given unemployment spell is 3.3 (not reported in the table). As a result, the average number of weeks on supplementary UI benefits during the unemployment spell is about 12 weeks, which is only 4 weeks less than the average unemployment duration for the non-recipients.

- Table 1 about here -

Women (married and singles) are more likely to experience periods on supplementary UI benefits during unemployment than men. This could be due to at least three things; first, it might just reflect that women on average are unemployed for longer periods of time than men, and therefore they are also more likely to experience a period of supplementary UI benefit receipt. Second, it may be because they have a stronger preference for working parttime, and third, it may be the case that the employers of women have higher demands for part-time workers and hence push women into these schemes. The average age among those flowing into unemployment is about 40, and supplementary UI benefit recipients are slightly older than non-recipients. Among UI funds, it is seen that those that are over-represented in supplementary UI benefits are mainly in the 'white-collar' and 'others' UI funds. Immigrants and their desecendants do not appear to be neither over- or underrepresented among supplementary UI benefit recipients. Finally, we observed that those receiving supplementary UI benefits were more dependent on public income transfers in the 52 weeks before becoming unemployed, but did not differ in terms of the time spent in unemployment. 


\section{$5 \quad$ Econometric Model}

The econometric analysis aims at estimating the causal effect of receiving supplementary UI benefits on the duration of unemployment, or alternatively, on the exit rate from unemployment (including periods of supplementary UI benefit receipt). This is done by exploiting the timing-of-events approach formalized by Abbring and Van den Berg (2003). Exploiting random variation in the observed moment of transition from full-time unemployment to part-time unemployment with supplementary UI benefits, this approach is ideal for separating selection from causal effects in a duration model context. Furthermore, it allows us to estimate time-varying as well as heterogeneous treatment effects of receiving supplementary UI benefits.

Hence, we consider receipt of supplementary UI benefits to be the treatment, which is undertaken during a spell of unemployment, and we then want to estimate the effect of this treatment on the exit rate from unemployment both during and after the receipt of the treatment.

Let $T_{u}$ be a continuous random variable measuring the time from becoming unemployed until exit from unemployment benefits. Data on $T_{u}$ are obviously censored for those who remained unemployed until the $24^{\text {th }}$ week of the year 2007 .

The hazard rate out of unemployment is assumed to be a Mixed Proportional Hazard (MPH), that is

$$
\theta_{u}\left(t \mid x, d_{1}(t), d_{2}(t), v_{u}\right)=\lambda_{u}(t) \exp \left[x \beta_{u}+d_{1}(t) \gamma_{1}+d_{2}(t) \gamma_{2}+v_{u}\right]
$$

Thus, the hazard function is defined as the product of a baseline hazard, $\lambda_{u}(t)$, depending on the elapsed unemployment duration, and a scaling function, depending on observed variables, $x$, unobserved characteristics $v_{u}$, and the two time-varying indicators for being in treatment, $d_{1}(t)$ (i.e. receiving supplementary benefits at time $t$ ), and for having received treatment, $d_{2}(t)$ (i.e. having received supplementary benefits before $t$ but is not receiving at $t$ ). The coefficients $\gamma_{1}$ and $\gamma_{2}$ thus capture the lock-in and treatment effects of the receipt of supplementary UI benefits on the hazard rate out of unemployment, respectively.

In order to allow an interpretation of $\gamma_{1}$ and $\gamma_{2}$ as causal effects, we have to take into account the potential endogeneity of receipt of supplementary UI benefits. Let $T_{p}$ denote the time from becoming unemployed until the person finds part-time employment and thus begins receiving supplementary UI benefits. Note that, by construction, $T_{u} \geq T_{p}$, since we consider periods with receipt of supplementary UI benefits to be part of the unemployment 
spell. Following the notation used above and specifying once again a MPH function, the transition rate into supplementary UI benefits is specified as

$$
\theta_{p}\left(t \mid x, v_{p}\right)=\lambda_{p}(t) \exp \left[x \beta_{p}+v_{p}\right] .
$$

The unobserved stochastic variables $v_{u}$ and $v_{p}$ are allowed to be correlated, which implies a correction for the potential endogeneity of the treatment status. Note that the random variation in the timing of the treatment identifies the causal effect of the treatment under the assumption that unobserved characteristics are time-invariant. Their distribution is specified as bivariate discrete with $2 \times 2$ mass-points. Moreover, note that due to the random variation in the timing of treatment, no exclusion restriction is necessary to identify the parameters of this model non-parametrically. The only assumption necessary, beyond the assumption of mixed proportionally hazards, is one of non-anticipation, that is, the individual is not supposed to know in advance the exact starting date of the part-time job, only its probability distribution. In reality, this assumption is of course always violated, but as long as the individual does not know the exact starting date too long in advance, this is generally not perceived as a large problem. The proportional hazard condition is needed to identify the unobserved heterogeneity term. In particular, (a) observing an apparent interaction between the scaling function and the baseline hazard, and (b) assuming proportionality in the hazard, it is possible to capture the observed non-proportionality by including the unobserved variables.

Let $C_{i}$ be a non-censoring indicator that takes the value of 1 if spell $i$ was completed by the end of the observation period. The likelihood function for individual $j$ with $N$ unemployment spells is specified as,

$$
L\left(v_{u}, v_{p}\right)=\prod_{i=1}^{N} L_{i}\left(v_{u}, v_{p}\right)
$$

where

$$
\begin{aligned}
L_{i}\left(v_{u}, v_{p}\right)= & \theta_{p}\left[t_{p i} \mid x_{i}, v_{p}\right]^{I\left[t_{p i}<t_{u i}\right]} \theta_{u}\left[t_{u i} \mid x_{i}, d_{1}\left(t_{u i}\right), d_{2}\left(t_{u i}\right), v_{u}\right]^{C_{i}} \\
& \times \exp \left\{-\int_{0}^{t_{p_{i}}} \theta_{p}\left[s \mid x_{i}, v_{p}\right] d s-\int_{0}^{t_{u i}} \theta_{u}\left[t \mid x_{i}, d_{1}(t), d_{2}(t), v_{u}\right] d t\right\}
\end{aligned}
$$

\section{Results}

In this section, we first describe the raw transition data in order to observe patterns in the data. We then proceed to discuss in some detail the selection 
equation and main parameters of interest from a model with homogeneous treatment effects across individuals. We then proceed to discuss results from a model with heterogeneous treatment effects, and we illustrate and analyze these results in different ways.

\subsection{Empirical Hazards}

In Figure 1, we plot the Kaplan-Meier hazard rates out of unemployment as a function of elapsed unemployment duration. Specifically, four empirical hazard functions are depicted: (a) the hazard rate to supplementary UI benefits, (b) the hazard out of unemployment for those not (yet) receiving supplementary UI benefits, (c) the hazard out of unemployment for those currently receiving supplementary UI benefits, and (d) the hazard out of unemployment for those who received supplementary UI benefits earlier in the current unemployment spell. Note that all the durations on the first axis are measured from the time of unemployment entry.

- Figure 1 about here -

The hazard rate into supplementary UI benefits is fairly large during the very early phases of unemployment, but it decreases over the first 20 unemployment weeks to a level of around $0.5 \%$.

Similarly, the hazard rate out of unemployment for those who have not (yet) received supplementary UI benefits is very large early in the unemployment spell but drops to a level around 2\% after 30-40 weeks of unemployment. It is also evident from the figure that current recipients of supplementary UI benefits have the lowest hazard rates out of unemployment among the three groups (recipients, non-recipients, past recipients) during the first year of unemployment, while those who have had a period of supplementary UI benefit receipt have the highest transition rate out of unemployment from the $6^{\text {th }}$ week of unemployment and onwards.

These descriptive findings thus suggest the presence of a lock-in effect reducing the transition rate out of unemployment while individuals are in treatment and a positive post-treatment effect. However, these differences in the raw empirical hazard rates cannot be interpreted as causal effects, since they may be driven by differences in observed and unobserved characteristics. The selection into supplementary UI benefits is discussed in the next section. 


\subsection{Selection Equation}

The results from the selection equation are presented in the $2^{\text {nd }}$ and $3^{\text {rd }}$ columns (coefficients and standard errors, respectively) of Table $2 .{ }^{8}$

- Table 2 about here -

Duration dependence is negative, as indicated in the raw empirical hazard of Figure 1. In accordance with our descriptive findings, women - married as well as single - have a much higher transition rate to part-time employment with supplementary UI benefits. Moreover, married men have a higher transition rate into the treatment state than single men. The same is the case for individuals aged 24 or below, while individuals aged 30-39 and 50-59 have the lowest transition rate into supplementary UI benefits. Given their weaker labour market attachment, subsidized part-time work may provide an effective way to accumulate work experience and obtain useful skills for young workers.

Compared to workers who are members of the metal workers UI fund and those who work in the construction industry, the members of other UI funds typically enter subsidized part-time work at higher rates. Particularly sizeable and positive effects are found for white-collar workers, academics, and 'others'. Non-western immigrants, the second generation in particular, are characterized by low hazards to supplementary UI benefits, something which was not evident from the raw data, while the western immigrants do not differ notably from the native Danes in this respect. Past public transfers have a dynamic effect which is hard to interpret, but adding the 3 coefficients, it is not evident that past public income transfer dependence in general has an impact. However, the number of weeks spent in unemployment during the past 2 years before the current unemployment spell has a distinct positive effect on the probability of entering supplementary UI benefit receipt.

\subsection{Homogeneous Model}

The $4^{\text {th }}$ and $5^{\text {th }}$ columns of Table 2 show the coefficients on the hazard rate out of unemployment. This hazard rate is uniformly decreasing until

\footnotetext{
${ }^{8}$ The results regarding the selection equation are taken from the full model with homogeneous treatment effects. The selection equation from the model with heterogeneous treatment effects shows almost identical results.
} 
52 weeks of unemployment, whereafter it appears fairly constant. Married men have the highest hazard rate out of unemployment, while single women have the lowest. Interestingly, married women have a higher transition rate out of unemployment than single men. The hazard rate is almost uniformly decreasing in age as found in several other studies. Unemployed workers who are members of the metal workers' UI fund or the construction workers' UI fund have higher transition rates out of unemployment than others, while those in the UI fund for (previously) self-employed individuals have the lowest hazard rates. As known from other studies, immigrants have lower exit rates than native Danes, especially those of Non-Western origin. The same holds for Non-Western $2^{\text {nd }}$ generation immigrants. Having recently spent time on public income transfers is associated with a lower hazard rate, while more unemployment weeks in the past surprisingly has a positive influence. Note, however, that these weeks are also included in the former week, so the implication is that spending time in unemployment is relatively better than spending time on other public income transfer schemes.

The two rows at the bottom of the table show the treatment effects, that is, the lock-in effect and the post-treatment effect. It is seen that, on average, current receipt of supplementary UI benefits causes a reduction in the transition rate out of unemployment of $55 \%(1-\exp (-0.791))$. On the other hand, having received supplementary UI benefits earlier in the unemployment spell causes an increase in the hazard rate of $30 \%$. This result immediately suggests that the net effect on unemployment duration will depend crucially on the length of the treatment period, and suggests moreover that attempts at reducing the treatment length may be beneficial, unless of course, the post-treatment effect depends on the length of the treatment period. In the next section, this issue is dealt with along with heterogeneous impacts in other dimensions.

\subsection{Heterogeneous Effects Model}

The results for the model with heterogeneous effects are presented in Table 3 . The table only shows parameters related to the effect of the treatment, while the other parameter estimates are available on request from the authors. The $2^{\text {nd }}$ and $3^{\text {rd }}$ columns show interaction effects of selected observed characteristics with the in-treatment indicator, while the $4^{\text {th }}$ and $5^{\text {th }}$ columns show interaction effects with the post-treatment indicator. ${ }^{9}$ Thus, the table

\footnotetext{
${ }^{9}$ The treatment indicators were interacted with all included variables, but those not reported here were not significant and therefore removed from the final model.
} 
provides a deeper analysis of how lock-in and treatment effects vary among workers with different characteristics.

- Table 3 about here -

First of all, note that the lock-in effect is present for the reference person, and it is of the same order of magnitude as was the case for the homogeneous effects model. Moreover, note that the lock-in effect is decreasing in the elapsed unemployment duration at the time when an individual starts receiving supplementary UI benefits (and working part-time). Thus, one year after entry into unemployment, the lock-in effect is reduced to $40 \%$ $(1-\exp (-0.73+0.00434 * 52))$ from $52 \%$ at the time of inflow into unemployment. We also tested for quadratic effects, but there were none.

Women (single or married) have a lock-in effect of $60 \%$ compared to the $52 \%$ of the reference single male, while married men have a lock-in effect of $56 \%$. The lock-in effect is less severe for workers below 24 and above 60, while it is particularly large for individuals who are members of the UI funds of the construction industry, white collar workers and academics.

Turning to the post-treatment effect, this leads to a $33 \%$ increase in the hazard rate out of unemployment. Having received treatment for one year during an unemployment spell increases the post-treatment effect to $63 \%$, i.e. almost a doubling. Recently, the rules have been changed so that the maximum period on supplementary UI benefits is 26 weeks, which will lead to a post-treatment effect of $47 \%$. Again, there was absolutely no evidence of a non-linear effect.

The post-treatment effect is smallest for married women and largest for single men. It is largest for the youngest age group, and for members of the UI fund for the (previously) self-employed.

In conclusion then, spending time in supplementary UI benefits (and working part-time) seems to be least beneficial for women and most beneficial for the young (and to some extent the old) age group. Moreover, we find that the lock-in effect is smaller in absolute terms the later during an unemployment spell a person participates in the treatment, and the post-treatment effect increases with the treatment duration. The latter implies an inherent conflict in the treatment; the longer the treatment lasts, the larger the accumulated lock-in effect becomes, but on the other hand the post-treatment effect also increases the treatment duration. This paradox can only be solved by looking at net effects on the expected remaining unemployment duration, to which we turn in the next section. 


\subsection{Expected Remaining Durations}

A consequence of a negative lock-in effect and a positive post-treatment effect is that the overall effect of subsidized part-time work on the expected remaining unemployment duration is ambiguous. It depends on the timing and duration of the treatment, and on the individual's characteristics. For these reasons, it is illustrative to compare expected remaining unemployment durations in counterfactual situations with and without periods of supplementary benefits. More specifically, we consider the following treatment effect:

$$
\begin{aligned}
\Psi\left(X, t_{p}, \Delta\right)= & E\left(T_{u}-t_{p} \mid X, T_{p}=t_{p}, \Delta, T_{u}>t_{p}\right) \\
& -E\left(T_{u}-t_{p} \mid X, T_{p}=\infty, T_{u}>t_{p}\right),
\end{aligned}
$$

where $t_{p}$ denotes the realised timing of the treatment, i.e. the time until entry into supplementary UI benefits, and $\Delta$ is the (maximum) duration of the supplementary UI benefit period. In other words, $\Psi\left(X, t_{p}, \Delta\right)$ measures the effect on the expected remaining unemployment duration of entering parttime work with supplementary UI benefit receipt at unemployment duration $t_{p}$ and staying there for (at most) $\Delta$ weeks, compared to the counterfactual of no treatment, for a worker with observed characteristics $X$.

We consider nine different treatments by varying $t_{p} \in\{7.5,15,30\}$ and $\Delta \in\{4,12,24\}$. These values describe the variation around the sample means of $t_{p}=15$ and $\Delta=12$. Using our model with the heterogeneous lock-in and treatment effects, we compute the net effects of these nine treatments for the subsample of workers in our sample who actually received supplementary benefits during a given unemployment spell. The results from this exercise are reported in Table $4 .{ }^{10}$ The first two columns of Table 4 characterize the treatment in question. Columns 3 and 4 report the sample averages of the expected remaining unemployment durations with and without the treatment, respectively. Their difference in column 5 is the average treatment effect on the treated. The remaining columns in Table 4 characterize the distribution of treatment effects across treated workers in the sample.

\footnotetext{
${ }^{10}$ Note that it is not possible to do the same for the actual treatments given to individuals in the sample, since we do not know the intended duration of treatments for individuals exiting unemployment while in treatment, nor do we know the intended re-entry rate into treatments for individuals leaving unemployment while having received treatment. In order to calculate the expected remaining duration, the entire treatment process during the unemployment spell must be known.
} 
- Table 4 about here -

As illustrated by the distributions in Table 4, the lock-in effect tends to dominate the post-treatment effect at longer treatment durations, while the treatment effects generally increase (in absolute value) with the elapsed unemployment duration at the time of treatment. It is also obvious that the optimal treatment duration is fairly low and that treatment durations above 3 months appear to lead to increasing remaining unemployment duration.

Turning to the distributions of the treatment effects, it is also obvious that there are individuals who gain from all the 9 treatments shown here, and in nearly all cases there are at least $25 \%$ of the treated who suffer from the treatment. The question of obvious interest now is who tend to benefit from supplementary UI benefit periods and who do not? To address this question, we report mean characteristics of workers in the $1^{\text {st }}$ and $10^{\text {th }}$ deciles of the treatment effect distribution in Table 5, where the treatment corresponds to the supplementary UI benefit period that starts after 15 weeks of full-time unemployment and lasting 12 weeks at maximum. The workers in the $1^{\text {st }}$ decile have the largest reduction in the expected remaining unemployment duration resulting from the treatment, and those in the $10^{\text {th }}$ decile have the largest increase in the expected remaining unemployment duration.

- Table 5 about here -

As expected from the estimation results, the $10^{\text {th }}$ decile is completely dominated by married women. Moreover, $56 \%$ of them are members of the white collar workers' UI fund, and $40 \%$ are members of the manufacturing industry workers' UI fund. They are all 30-59 years old.

Those who gain most from taking a part-time job with supplementary UI benefits are less clearly identified; both men and women are among the 'winners'. Still, more than $60 \%$ of the 'winners' are below 30, and they are members of the UI funds in the categories 'Others', '(previously) self-employed', and 'trade'. Finally, there is a fairly large fraction of Non-Western immigrants among the 'winners', suggesting the use of part-time subsidized work as a way into the labour market for immigrants.

\subsection{Robustness Checks}

In the data, some workers move between full-time unemployment and subsidized part-time work almost on a regular basis. It seems likely that these 
workers return repeatedly to the same subsidized job, which of course has very different implications than a sequence of different subsidized jobs. This raises the question how such observations should be treated in the data. In absence of a definite answer, we check the robustness of our results with respect to different configurations of treatment and unemployment durations. Here we consider variation in the lock-in and treatment effects obtained from the homogenous effect model to minimize the number of additional parameter estimates.

First, we simply ignore all periods of supplementary benefits shorter than 3 or 5 weeks (which are thus regarded as regular full-time unemployment). These results are shown in the rows $\mathrm{B}$ and $\mathrm{C}$ of Table 6 . Compared to our baseline treatment effects in the $1^{\text {st }}$ column, both the lock-in and posttreatment effects fall in absolute value. Second, we combine periods on supplementary UI benefits with a short distance of less than 2 or 4 weeks of full-time unemployment into one supplementary UI benefit period (thus treating the interruptions as supplementary benefit periods). As seen in rows $\mathrm{D}$ and $\mathrm{E}$, both the lock-in and treatment effects get stronger compared to the baseline values. In all cases, therefore, a more (less) negative lock-in effect is compensated by a larger (smaller) positive post-treatment effect, suggesting that the effect on the expected duration is relatively robust.

- Table 6 about here -

Finally, recall that the unemployment spells which begin with a supplementary UI benefit period lasting more than one week have been excluded from our sample. As a robustness check, we also add these spells to the analysis by generating an artificial 0.1-week period of full-time unemployment to the beginning of such unemployment periods. It turns out that including these spells in the analysis only has a moderate effect on the estimates (see specification $\mathrm{F}$ ).

Summarising, different definitions of supplementary UI benefit periods and the inclusion of those who start out on suppementary UI benefits does not seem to alter our results qualitatively.

\section{Conclusions}

The present study provides results that do not encourage a general implementation of supplementary unemployment insurance benefits, such as is 
the case in e.g. Denmark and Finland. The sign and magnitude of this effect vary with individual characteristics and with the timing and length of receipt of supplementary UI benefits. On average, in our sample of Danish workers, receiving supplementary UI benefits while working part-time reduces unemployment duration. However, due to the presence of a severe lock-in effect, longer spells of subsidized work tend to prolong unemployment duration, even though the post-treatment effect also increases with respect to the treatment duration. Moreover, it tends to increase unemployment duration for married women, white collar workers and manufacturing workers. This suggests a notable degree of moral hazard and free-riding behaviour within these groups.

However, the effects are much better for certain other groups of workers, particularly those with short subsidized working periods. Young workers and $1^{\text {st }}$ generation Non-Western immigrants typically benefit from the receipt of supplementary UI benefits in terms of reduced expected unemployment duration. This implies that, at least for some types of workers, subsidized part-time jobs may work as stepping stones to regular employment. Specifically, it makes sense that young workers and immigrants can benefit from short part-time jobs since they need (a) to develop their work experience and skills, (b) to enlarge their network among employed workers, and (c) to signal their motivation and knowledge in order to increase the number of job offers and ultimately improve upon their labour market career prospects.

A general lesson of our analysis is that the current uniform scheme of supplementary UI benefits on average works well, but it may still be improved. Specifically, the large degree of impact heterogeneity implies some potential policy improvements. More intensive monitoring of job search efforts could be used to mitigate the adverse effects found for some groups. The supplementary UI benefit scheme could - to some extent - be targeted at the groups that are most likely to benefit from it. If all groups of unemployed applicants have to be covered, the maximum duration and compensation level could be varied across the groups.

According to what has been argued, it would be interesting to test a reduction in the generosity of these income compensation schemes, in terms of coverage, wage percentage amount and duration of benefits. In the case of such a policy change, it would be possible to estimate more accurately the causal effects associated with this change and potentially identify structural behavioural models among workers. It could lead to more targeted unemployment insurance instruments and a notable saving of public expenditure to eventually devote towards other social priorities.

From a cost-benefit perspective, the fact that the policy overall reduces 
unemployment duration almost surely implies that a cost-benefit analysis would favour it; workers who would otherwise be unemployed are 1) contributing to the aggregate production, and 2) requiring fewer UI benefits than full-time unemployed workers. Specifically, even a certain increase in unemployment duration might still support the policy, since the reduction in UI benefits at least to some extent outweighs the loss of production. Naturally, there may be various substitution effects, but in the sense that this policy increases effective labour supply, and that it may fill a gap in ensuring labour supply for (part-time) jobs that would not be filled otherwise, it is hard to see how a cost-benefit analysis would be unfavourable towards it. Still, the outcome of a cost-benefit analysis might be even more beneficial, if some of the improvements discussed above were implemented.

Finally, it is worth emphasizing that the present analysis does not allow for general equilibrium effects. Aggregate effects may arise if the provision of supplementary UI benefits also influences the relative supply of part-time, temporary, and regular jobs. That is surely the main limitation one can find in the outlined reduced-form duration analysis.

\section{References}

[1] Abbring, J. H., and G. J. Van den Berg (2003), "The non-parametric identification of treatment effects in duration models", Econometrica $71,1491-1517$.

[2] Booth, A. L., J.J. Dolado and J. Frank (2002), "Symposium on Temporary Work: Introduction", The Economic Journal 112, F181-F188.

[3] Holen, A., and S. Horowitz (1974), "Partial Unemployment Insurance Benefits and the Extent of Partial Unemployment" The Journal of Human Resources, Vol. 9, No. 3, 420-422.

[4] Houseman, S.N., A.L. Kalleberg and G.A. Erickcek (2003), "The role of temporary help employment in tight labour markets", Upjohn Institute Staff Working Paper 01-73.

[5] Heinrich, C. J., P. R. Mueser, and K. R. Troske (2005), "Welfare to temporary work: Implications for labour market outcomes", The Review of Economics and Statistics 87, 154-173.

[6] Kyyrä, T. (2008), "Partial Unemployment Insurance Benefits and the Transition Rate to Regular Work", VATT Discussion Paper 440. 
[7] Larsson, L., L. Lindqvist, and O. N. Skans (2005), "Stepping-stones or deadends? An analysis of Swedish replacement contracts", IFAU Working Paper 2005:18.

[8] McCall, B. (1996), "Unemployment insurance rules, joblessness, and part-time work", Econometrica 64, 647-682.

[9] McCall, B. (1997), "The Determinants of Full-Time versus Part-Time Reemployment following Job Displacement", Journal of labour Economics, 15 (4), 714-734.

[10] Møller, I. H. and J. Lind (2000). 'The labour market in process of change? Some critical comments'. In J. Lind and D. Mortimer (eds.), Worlds of Employment. Aalborg.

[11] Munts, R. (1970), "Partial benefit schedules in unemployment insurance: Their effects on work incentives", The Journal of Human Resources $5,160-176$.

[12] Rasmussen, E., J. Lind and J. Visser (2004), "Divergence in Part-Time Work in New Zealand, the Netherlands and Denmark", British Journal of Industrial Relations, 42:4, 637-658.

[13] Rosholm, M. (2008), "Experimental Evidence on the Nature of the Danish Employment Miracle", IZA Discussion Paper 3620, IZA, Bonn.

[14] Staghøj, J., M. Svarer and M. Rosholm (2007), "A Statistical Programme Assignment Model", IZA Discussion Paper 3165, IZA, Bonn.

[15] Storrie, D. (2002), "Temporary agency work in the European Union", Department of Economics, University of Gothenburg: Mimeo.

[16] Svarer, M. (2007), "The Effect of Sanctions on the Job Finding Rate: Evidence from Denmark", IZA Discussion Paper 3015, IZA, Bonn. 


\begin{tabular}{|c|c|c|c|c|}
\hline \multicolumn{5}{|c|}{ Table 1: Sample Statistics } \\
\hline & \multicolumn{2}{|c|}{ Non-recipients } & \multicolumn{2}{|c|}{ Recipients } \\
\hline & Mean & Std. Dev. & Mean & Std. Dev. \\
\hline \multicolumn{5}{|l|}{ Family status: } \\
\hline Married woman & 0.300 & 0.458 & 0.371 & 0.483 \\
\hline Married man & 0.268 & 0.443 & 0.186 & 0.389 \\
\hline Single woman & 0.175 & 0.380 & 0.261 & 0.439 \\
\hline Single man & 0.257 & 0.437 & 0.182 & 0.386 \\
\hline \multicolumn{5}{|l|}{ Age: } \\
\hline less than 25 & 0.079 & 0.270 & 0.087 & 0.282 \\
\hline $25-29$ & 0.175 & 0.380 & 0.169 & 0.374 \\
\hline $30-39$ & 0.325 & 0.469 & 0.303 & 0.459 \\
\hline $40-49$ & 0.217 & 0.412 & 0.223 & 0.417 \\
\hline $50-59$ & 0.184 & 0.387 & 0.196 & 0.397 \\
\hline above 59 & 0.020 & 0.141 & 0.023 & 0.149 \\
\hline \multicolumn{5}{|l|}{ UI fund: } \\
\hline Construction industry & 0.030 & 0.170 & 0.012 & 0.110 \\
\hline Manufacturing industry & 0.363 & 0.481 & 0.271 & 0.445 \\
\hline Technicians & 0.048 & 0.214 & 0.043 & 0.203 \\
\hline White collar workers & 0.114 & 0.318 & 0.173 & 0.378 \\
\hline Academics & 0.081 & 0.273 & 0.093 & 0.291 \\
\hline Others & 0.167 & 0.323 & 0.219 & 0.399 \\
\hline Self-employed & 0.024 & 0.152 & 0.026 & 0.159 \\
\hline Metal Industry & 0.061 & 0.239 & 0.029 & 0.166 \\
\hline Trade & 0.113 & 0.316 & 0.134 & 0.341 \\
\hline \multicolumn{5}{|l|}{ Nationality: } \\
\hline Danish & 0.907 & 0.290 & 0.904 & 0.295 \\
\hline Western immigrant & 0.024 & 0.154 & 0.027 & 0.163 \\
\hline Non-Western Immigrant & 0.060 & 0.237 & 0.060 & 0.237 \\
\hline 2nd gen. Western immigrant & 0.004 & 0.065 & 0.005 & 0.068 \\
\hline 2nd gen. Non-Western immigrant & 0.005 & 0.069 & 0.004 & 0.066 \\
\hline \multicolumn{5}{|l|}{ Public income transfer: } \\
\hline 0-1 year ago & 0.329 & 0.318 & 0.408 & 0.349 \\
\hline 1-2 years ago & 0.447 & 0.375 & 0.441 & 0.389 \\
\hline $2-3$ years ago & 0.408 & 0.391 & 0.436 & 0.402 \\
\hline \multicolumn{5}{|l|}{ Fraction of time spent unemployed } \\
\hline $0-2$ years ago & 0.281 & 0.258 & 0.284 & 0.277 \\
\hline Unemployment duration (in weeks) & 16.3 & 31.7 & 48.1 & 51.0 \\
\hline Number of spells & 190,678 & & 43,392 & \\
\hline
\end{tabular}




\begin{tabular}{|c|c|c|c|c|}
\hline & \multicolumn{2}{|c|}{ Selection equation } & \multicolumn{2}{|c|}{$\begin{array}{l}\text { Hazard out of } \\
\text { unemployment }\end{array}$} \\
\hline & Cofficient & Std.err. & Cofficient & Std.err. \\
\hline \multicolumn{5}{|l|}{ Baseline hazard (weeks): } \\
\hline $0-4$ & -3.501 & 0.038 & -1.743 & 0.015 \\
\hline $4-8$ & -3.983 & 0.040 & -2.436 & 0.016 \\
\hline $8-12$ & -4.239 & 0.042 & -2.646 & 0.017 \\
\hline $12-16$ & -4.394 & 0.043 & -2.730 & 0.017 \\
\hline $16-20$ & -4.521 & 0.045 & -2.793 & 0.018 \\
\hline $20-25$ & -4.601 & 0.046 & -2.874 & 0.018 \\
\hline $25-35$ & -4.745 & 0.044 & -2.968 & 0.017 \\
\hline $35-52$ & -4.909 & 0.045 & -3.124 & 0.017 \\
\hline $52-79$ & -5.028 & 0.046 & -3.254 & 0.018 \\
\hline 79-104 & -5.201 & 0.055 & -3.297 & 0.020 \\
\hline $104-156$ & -5.240 & 0.056 & -3.267 & 0.020 \\
\hline 156- & -5.309 & 0.072 & -3.002 & 0.022 \\
\hline \multicolumn{5}{|l|}{ Family status (vs. single man): } \\
\hline Married woman & 0.477 & 0.018 & 0.084 & 0.007 \\
\hline Married man & 0.154 & 0.019 & 0.233 & 0.008 \\
\hline Single woman & 0.539 & 0.019 & -0.054 & 0.008 \\
\hline \multicolumn{5}{|l|}{ Age (vs.30-39): } \\
\hline less than 25 & 0.313 & 0.024 & 0.086 & 0.011 \\
\hline $25-29$ & 0.091 & 0.018 & 0.093 & 0.007 \\
\hline $40-49$ & 0.129 & 0.016 & -0.100 & 0.006 \\
\hline $50-59$ & -0.006 & 0.017 & -0.285 & 0.007 \\
\hline above 59 & 0.122 & 0.036 & -0.293 & 0.018 \\
\hline \multicolumn{5}{|l|}{ UI fund (vs. Metal): } \\
\hline Construction industry & 0.134 & 0.055 & -0.014 & 0.020 \\
\hline Manufacturing industry & 0.571 & 0.027 & -0.098 & 0.009 \\
\hline Technicians & 0.600 & 0.038 & -0.345 & 0.014 \\
\hline White collar workers & 1.178 & 0.030 & -0.097 & 0.011 \\
\hline Academics & 0.890 & 0.032 & -0.287 & 0.013 \\
\hline Others & 1.028 & 0.029 & -0.379 & 0.011 \\
\hline Self-employed & 0.409 & 0.042 & -0.610 & 0.020 \\
\hline Trade & 0.670 & 0.031 & -0.339 & 0.012 \\
\hline \multicolumn{5}{|l|}{ Nationality (vs. Danish): } \\
\hline Western immigrant & -0.075 & 0.036 & -0.145 & 0.016 \\
\hline Non-Western Immigrant & -0.187 & 0.026 & -0.373 & 0.011 \\
\hline 2nd gen. Western immigrant & 0.108 & 0.088 & -0.022 & 0.037 \\
\hline 2nd gen. Non-Western immigrant & -0.371 & 0.101 & -0.305 & 0.048 \\
\hline \multicolumn{5}{|c|}{ Fraction of time on public income transfers: } \\
\hline $0-1$ year ago & 0.107 & 0.021 & -0.812 & 0.009 \\
\hline $1-2$ years ago & -0.282 & 0.024 & 0.551 & 0.010 \\
\hline $2-3$ years ago & 0.124 & 0.019 & -0.050 & 0.007 \\
\hline \multicolumn{5}{|l|}{ Fraction of time spent unemployed } \\
\hline $0-2$ years ago & 0.117 & 0.028 & 0.285 & 0.013 \\
\hline \multicolumn{5}{|l|}{ Treatment Effects: } \\
\hline Lock-in & & & -0.791 & 0.013 \\
\hline Post-treatment & & & 0.265 & 0.007 \\
\hline
\end{tabular}

Note: Numbers in bold are statistically significant at the $5 \%$ level. The model includes also indicators for county of residence, year and quarter of entry into unemployment, and parameters for the distribution of unobserved characteristics. 
Table 3: Heterogeneous treatment effects

\begin{tabular}{|c|c|c|c|c|}
\hline & \multicolumn{2}{|c|}{ Lock-in } & \multicolumn{2}{|c|}{ Post-treatment } \\
\hline & Cofficient & Std.dev. & Cofficient & Std.dev. \\
\hline Effect for reference person & -0.730 & 0.065 & 0.285 & 0.028 \\
\hline Elapsed unemployment duration/100 & 0.434 & 0.053 & & \\
\hline Accumulated past weeks of supp. UI ben./100 & & & 0.386 & 0.057 \\
\hline \multicolumn{5}{|l|}{ Family status (vs. single man): } \\
\hline Married woman & -0.213 & 0.036 & -0.159 & 0.018 \\
\hline Married man & -0.100 & 0.041 & -0.065 & 0.019 \\
\hline Single woman & -0.188 & 0.038 & -0.096 & 0.019 \\
\hline \multicolumn{5}{|l|}{ Age (vs.30-39): } \\
\hline less than 25 & 0.309 & 0.047 & 0.318 & 0.023 \\
\hline $25-29$ & 0.078 & 0.036 & 0.136 & 0.018 \\
\hline $40-49$ & -0.007 & 0.031 & -0.005 & 0.016 \\
\hline $50-59$ & -0.004 & 0.033 & -0.032 & 0.018 \\
\hline above 59 & 0.221 & 0.078 & 0.098 & 0.051 \\
\hline \multicolumn{5}{|l|}{ UI fund (vs. Metal): } \\
\hline Construction industry & -0.457 & 0.157 & 0.061 & 0.056 \\
\hline Manufacturing industry & 0.026 & 0.061 & -0.052 & 0.027 \\
\hline Technicians & -0.093 & 0.080 & -0.005 & 0.040 \\
\hline White collar workers & -0.271 & 0.065 & -0.029 & 0.030 \\
\hline Academics & -0.198 & 0.072 & 0.040 & 0.032 \\
\hline Others & -0.069 & 0.064 & 0.040 & 0.029 \\
\hline Self-employed & 0.391 & 0.087 & 0.273 & 0.048 \\
\hline Trade & 0.052 & 0.067 & 0.079 & 0.031 \\
\hline
\end{tabular}

Note: Numbers in bold are statistically significant at the $5 \%$ level. The reference person is a single male aged 30-39 and member of the Metal Industry workers' UI fund, has elapsed unemployment duration of 0 when starting treatment and 0 weeks of accumulated treatment in the past when finishing treatment. 
Table 4: Expected remaining durations and treatments effects

\begin{tabular}{|c|c|c|c|c|c|c|c|c|c|c|c|}
\hline \multicolumn{2}{|c|}{ Treatment } & \multirow{2}{*}{\multicolumn{3}{|c|}{$\begin{array}{c}\text { Average expected remaining } \\
\text { unemployment duration } \\
\end{array}$}} & \multicolumn{7}{|c|}{ Percentiles of treatment effects } \\
\hline \multirow[b]{2}{*}{$t_{p}$} & \multirow[b]{2}{*}{$\Delta$} & & & & & & & & & & \\
\hline & & $T_{p}=t_{p}$ & $T_{p}=\infty$ & $\Psi\left(X, t_{p}, \Delta\right)$ & p5 & p10 & p25 & p50 & p75 & p90 & p95 \\
\hline 7.5 & 4 & 25.0 & 31.5 & -6.4 & -19.4 & -14.9 & -9.1 & -4.8 & -1.9 & 0.2 & 0.9 \\
\hline 7.5 & 12 & 30.8 & 31.5 & -0.7 & -13.3 & -8.8 & -3.2 & 1.0 & 3.6 & 5.6 & 6.3 \\
\hline 7.5 & 24 & 36.5 & 31.5 & 5.0 & -8.1 & -3.4 & 2.5 & 6.6 & 9.4 & 11.2 & 12.8 \\
\hline 15 & 4 & 20.1 & 27.2 & -7.1 & -20.4 & -15.8 & -9.9 & -5.5 & -2.5 & -0.2 & 0.5 \\
\hline 15 & 12 & 24.9 & 27.2 & -2.3 & -15.8 & -11.1 & -5.1 & -0.6 & 2.4 & 4.6 & 5.2 \\
\hline 15 & 24 & 30.6 & 27.2 & 3.4 & -10.3 & -5.5 & 0.6 & 5.1 & 8.0 & 10.1 & 11.5 \\
\hline 30 & 4 & 8.8 & 16.6 & -7.8 & -21.4 & -16.8 & -10.8 & -6.2 & -3.1 & -0.7 & 0.0 \\
\hline 30 & 12 & 12.8 & 16.6 & -3.8 & -17.4 & -12.8 & -6.7 & -2.1 & 1.0 & 3.3 & 4.1 \\
\hline 30 & 24 & 17.9 & 16.6 & 1.3 & -12.9 & -8.0 & -1.8 & 3.0 & 6.2 & 8.5 & 9.7 \\
\hline
\end{tabular}




\begin{tabular}{|c|c|c|}
\hline \multicolumn{3}{|c|}{$\begin{array}{c}\text { Table 5: Mean characteristics of the treated workers in } \\
\text { the 1st and 10th deciles of the treatment effect } \\
\text { distribution }\end{array}$} \\
\hline & $1^{\text {st }}$ decile & $10^{\text {th }}$ decile \\
\hline \multicolumn{3}{|l|}{ Family status: } \\
\hline Married woman & 0.182 & 0.910 \\
\hline Married man & 0.121 & 0.027 \\
\hline Single woman & 0.366 & 0.064 \\
\hline Single man & 0.330 & 0.000 \\
\hline \multicolumn{3}{|l|}{ Age: } \\
\hline less than 25 & 0.406 & 0.000 \\
\hline $25-29$ & 0.214 & 0.007 \\
\hline $30-39$ & 0.105 & 0.404 \\
\hline $40-49$ & 0.091 & 0.303 \\
\hline $50-59$ & 0.128 & 0.285 \\
\hline above 59 & 0.056 & 0.000 \\
\hline \multicolumn{3}{|l|}{ Ul fund: } \\
\hline Construction industry & 0.003 & 0.009 \\
\hline Manufacturing industry & 0.065 & 0.392 \\
\hline Technicians & 0.037 & 0.008 \\
\hline White collar workers & 0.016 & 0.561 \\
\hline Academics & 0.091 & 0.016 \\
\hline Others & 0.253 & 0.010 \\
\hline Self-employed & 0.210 & 0.000 \\
\hline Metal Industry & 0.016 & 0.005 \\
\hline Trade & 0.308 & 0.000 \\
\hline \multicolumn{3}{|l|}{ Nationality: } \\
\hline Danish & 0.825 & 0.952 \\
\hline Western immigrant & 0.032 & 0.021 \\
\hline Non-Western Immigrant & 0.119 & 0.021 \\
\hline 2nd gen. Western immigrant & 0.004 & 0.005 \\
\hline 2nd gen. Non-Western immigrant & 0.020 & 0.001 \\
\hline \multicolumn{3}{|c|}{ Fraction of time on public income transfers: } \\
\hline $0-1$ year ago & 0.505 & 0.345 \\
\hline 1-2 years ago & 0.320 & 0.523 \\
\hline $2-3$ years ago & 0.352 & 0.483 \\
\hline $\begin{array}{l}\text { Fraction of time spent unemployed } \\
0-2 \text { years ago }\end{array}$ & 0.181 & 0.344 \\
\hline
\end{tabular}


Table 6: Robustness Analysis

\begin{tabular}{lrrrr} 
& Coeff. & Std.dev & Coeff. & Std.dev \\
\hline Specification: & -0.791 & 0.013 & 0.265 & 0.007 \\
A. Baseline model & -0.465 & 0.012 & 0.223 & 0.009 \\
B. SUIB subspells shorter than 3 weeks ignored & -0.217 & 0.012 & 0.166 & 0.011 \\
C. SUIB subspells shorter than 5 weeks ignored & -0.887 & 0.012 & 0.341 & 0.007 \\
D. F-T unempl. subspells shorter than 2 weeks ignored & -1.033 & 0.012 & 0.454 & 0.007 \\
E. F-T unempl. subspells shorter than 4 weeks ignored & -0.771 & 0.011 & 0.239 & 0.007 \\
F. Workers immediately on SUIB included & & & &
\end{tabular}


Figure 1. Empirical hazard rates into supplementary UI benefits and out of unemployment

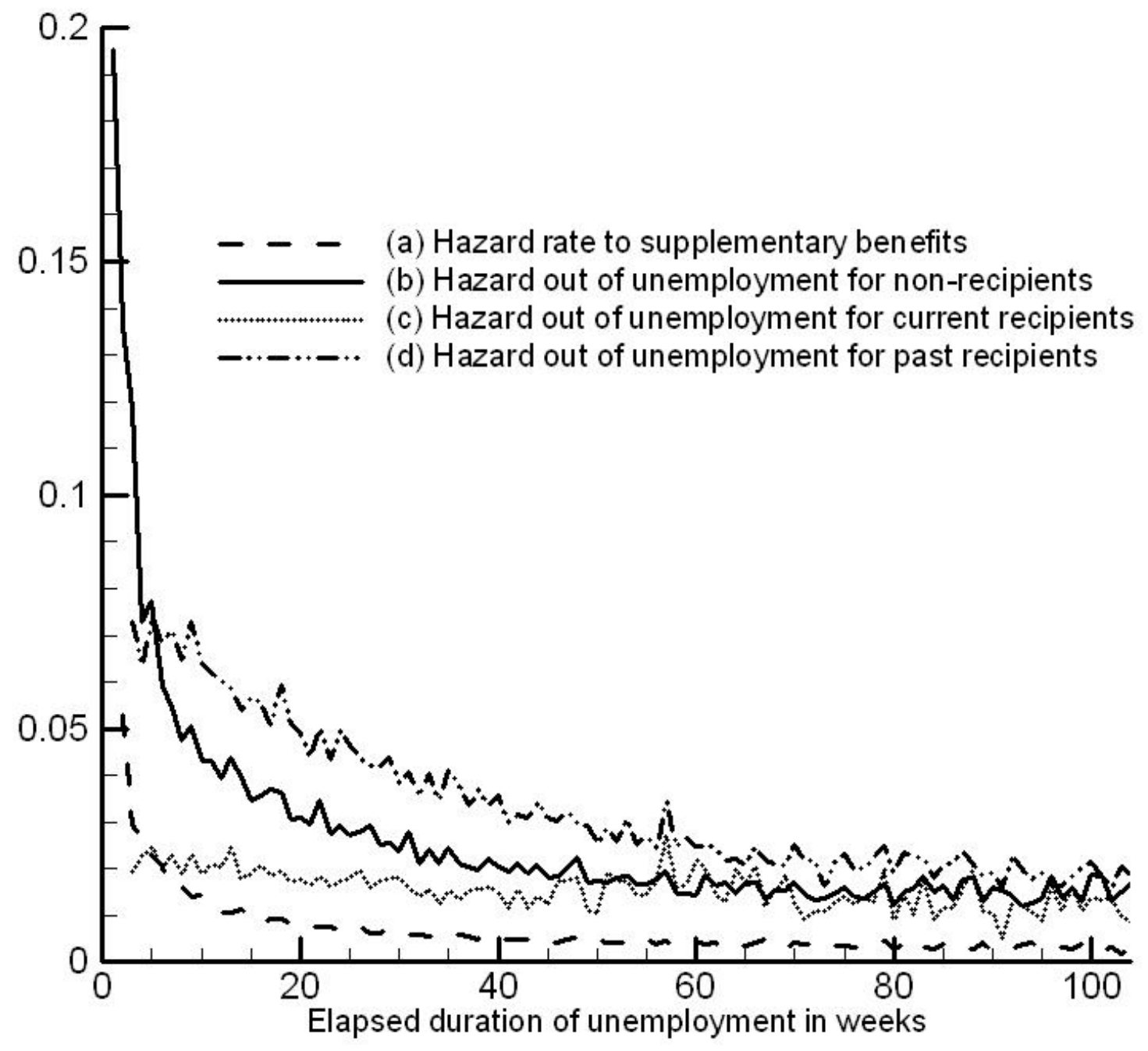

